\title{
Avian Influenza and Employment Decisions of Poultry Farmers in the Federal Capital Territory of Nigeria
}

\author{
Hassan Ishaq Ibrahim (Corresponding author) \\ Department of Agricultural Economics and Extension, Faculty of Agriculture \\ Nasarawa State University Keffi, Nigeria \\ Shabu- Lafia Campus PMB 135 Lafia, Nasarawa State, Nigeria
}

Tel: 234-080-3698-0580Ｅ-mail: hassibrahim@yahoo.com

Hussaini Iliyasu

FCT $3^{\text {rd }}$ National Fadama Development Project of Agricultural and Rural Development Secretariat Gwagwalada, P.M.B 630, Abuja, Nigeria

Tel: 234-080-3642-6507 E-mail: hussliycdo@yahoo.com

\author{
Hussaini Yusuf Ibrahim \\ Department of Agricultural Economics and Extension, Faculty of Agriculture \\ Nasarawa State University Keffi, Nigeria \\ Shabu- Lafia Campus PMB 135 Lafia, Nasarawa State, Nigeria
}

Tel: 234-080-6254-2802Ｅ-mail: Hussein464@yahoo.com

Napoleon D. Saingbe

College of Agriculture, Lafia Nasarawa State, Nigeria

\begin{abstract}
The outbreak of Avian Influenza in Nigeria has led to job losses, health problems, reduction in expected income of poultry farmers and a decrease in the demand for poultry products. This study was designed to determine the monetary value of stock lost, identify the determinants of the future employment decisions and the constraints faced by poultry farmers in the Federal Capital Territory of Nigeria. Data for the study was collected from 40 poultry farmers who have suffered losses due to the outbreak of the disease. The total monetary value of the stock lost in the study area as at 2007 was $\$ 142,741$, $000.45 \%$ of the respondents have abandoned poultry production while $32.5 \%$ have reduced the size of their poultry business. Furthermore, only $22.5 \%$ have restarted their poultry business without reducing the quantity of the initial stock before the outbreak of the disease. The determinants of the decision to abandon were; amount of compensation received, educational level of the poultry farmer and total number of stock lost. The factors influencing the decision to reduce the scale of operation were; level of education of the farmer, years of experience in poultry production and the amount of compensation received from government. The post Avian Influenza outbreak constraints faced by the farmers were; inadequate compensation, low patronage by customers and low level of accessibility to agricultural credit institutions.
\end{abstract}

Keywords: Avian influenza, Employment decisions, Poultry farmers, Nigeria

\section{Introduction}

The importance of poultry production in the national economics of developing countries and its role in improving the nutritional status and income of many small scale farmers and landless communities has been recognized by various scholars and rural development agencies in the last two decades (Adegbola 1990; FAO, 1990). However, the growth in the poultry sector is being threatened by problems facing livestock production which includes high cost of production and outbreak of diseases which recently includes the Avian Influenza or Bird flu. Avian influenza is an acute highly fatal 
disease of chickens, turkey, ducts, wild birds, geese and water fowls (Hagan and Brunner, 1988). It is caused by a virus usually found in wild migratory water birds and primarily affects all ages of domestic poultry. Prior to January 2006, there was no report of avian influenza in Nigeria and there was no evidence to suggest the presence of the disease in the country. The first suspected case was reported at Sambawa farms, a semi commercial farm situated in Kaduna State of Nigeria on January $16^{\text {th }} 2006$ and was finally confirmed on February $7^{\text {th }} 2006$ by the National Veterinary Research Institute, Vom (Pan-African Control of Epizootics, 2006).

The spread of the disease from three States in March 2006 to 13 States including the Federal Capital Territory as at May 2006 is instructive in the quality and adequacy of response and the capability of the country to deal with the problem. It also suggests that recovery and restricting efforts should not be delayed until the disease is unambiguously stamped out (UNDP, 2006). The incidence of the disease in a country like Nigeria ( a country whose most village households maintain free range flocks of poultry as a source of income and food) was a "shock" to poultry farmers, consumers and the economy because the impact ranges from changes in market demand, market supply and finance to external effects (UNDP, 2006). Thus both the productive and consumptive patterns of the rural and urban households are at risk in the event of a virulent disease outbreak such as avian influenza (Obayelu, 2007).

The first reported case of Avian influenza in the Federal Capital Territory Abuja was at Bwari Area Council on the $2^{\text {nd }}$ of February 2006 followed by Kuje area council on the $14^{\text {th }}$ of February 2006 and the Municipal area council on the $15^{\text {th }}$ of February 2006. Various attempts were made to stop the spread of the disease. Olarenwaju (2006) reported that poultry farmers in Nigeria have been affected negatively by the outbreak of avian influenza. Many people refused to eat chicken and eggs to avoid being exposed to the risk of human infection. Moreover, the closure of affected farms has resulted to unemployment. Olarenwaju (2006) quoted the World Bank as saying that a severe avian influenza pandemic may cost the world a whopping \$1.25trillion and may result in the death of about 70 million people. You and Diao (2006) analyzed the potential economic impacts of avian influenza in West Africa, taking Nigeria as an example. They concluded that, depending on the size of the affected areas, the direct impact of the spread the disease along the two major migratory bird flyways would be the loss of about $4 \%$ of national chicken production. The study estimates that Nigerian chicken production would fall by $21 \%$ and chicken farmers would lose US\$250 million of revenue if the worst-case scenario occurred. According to Obayelu (2007) about $75 \%$ of poultry farmers in the Federal Capital Territory were found to have stopped ordering for new birds to their farms and were preparing to leave the poultry business for other jobs the moment they disposed off the birds on their farms. About 22, 810 birds have been depopulated as at the end of 2007 from 609 farms and a compensation of over $\$ 11,472.800$ has been paid to the farmers in the Federal Capital Territory alone at \$250 per chicken\} (Abuja Echo, 2007). It was estimated that farmers lost millions of naira and many workers lost their jobs thus adversely affecting their dependants in form of drop out of schools, starvation, social inactiveness and quarrels in various families. (Abuja Echo, 2007). Saidu et al (2008) reported that a total of 480,378 birds were lost in 34 outbreaks in four states under study between the period of January and March 2006. Chickens accounted for more than $99 \%$ of all the birds affected followed by guinea fowls and turkeys. More than $60 \%$ of the birds affected were adults. Raufu et al (2009) also reported a significant difference in the socio-economic and level of income of affected and unaffected poultry farms in Ogun State, Nigeria. Fasina et al (2009) in their study on Avian Influenza Risk Perception among Poultry Workers in Nigeria observed that the respondents were more concerned about the effect of Avian Influenza on financial preservation of business interests than on public health risk.

Further more while various efforts since the outbreak of the disease has contributed on issues of prevention, control and eradication and more importantly prevention of human cases, little attention has been paid to the future employment and production decisions of affected poultry farmers. The aim of this study was therefore to assess the employment decisions of poultry farmers after the outbreak of avian influenza. The specific objectives were to estimate the monetary value of poultry birds lost to the disease, determine the post avian influenza outbreak employment options of poultry farmers, identify the factors that determine the employment options of the poultry farmers and to identify the post avian influenza outbreak constraints in the study area.

\section{Materials and methods}

The study was conducted in the Federal Capital Territory (FCT) Abuja, Nigeria. The area covers an area of about 8,000 Square Kilometers and has population of 1,405,201 persons (NPC, 2006). The FCT's natural endowment such as its rolling hills, isolated land and endearing feature makes it a delight. The savanna grassland of the north and the middle belt, the richness of the tropical rain forest of the south and an equatorial climate all combined; make the FCT a soil rich agricultural heaven (FCT ADP, 2007). Four area councils where there was a reported outbreak of Avian Influenza namely Gwagwalada Area Council, Municipal area Council, Bwari Area Council and Kuje Area Council were purposively selected for the study. 10 poultry farmers who suffered losses were randomly selected from each of the affected Area Councils. Therefore a total of 40 poultry farmers were used for the study. Primary data were used for the study; this was collected with the aid of a structured questionnaire which was administered to the poultry farmers. Data were collected over a period of 2 weeks by trained enumerators. Data were collected on farmers' socio-economic characteristics, 
monetary value of stock lost, employment options and post avian influenza outbreak constraints. Data analysis was done with the aid of descriptive statistics and Multinomial logit model. The model was fitted and estimated using multinomial logistic regression. A multinomial logistic regression pinpoints determinants affecting the probability for the choice of the future employment decisions of the poultry farmers. The dependent variable reflects the three likely employment decisions: continuation with poultry production, abandoning of poultry production, and reduction of the scale of production. The dependent can thus take three levels $(0,1$ and 2$)$. ' 0 ' represents the reference group or the group that continued production; ' 1 ' represents the group that abandoned production and ' 2 ' represents the group of those that have reduced their scale of poultry production. According to Maddala (1983), the model makes the choice of probabilities on individual's characteristics of the respondents (poultry farmers). Following Babcock et al., (1995), the basic model was specified as follows;

$$
\mathrm{P}_{\mathrm{ij}}=\frac{e_{j i}^{\beta X}}{j}
$$

where $\mathrm{i}=1,2-------n$ variables; $\mathrm{k}=0,1,-------\mathrm{j}$ groups; and $\beta_{j}=$ a vector of parameters that relates the $\mathrm{X}_{\mathrm{i}}{ }^{\text {'s }}$ to the probability of being in group $\mathrm{j}$ where there are $\mathrm{j}+\mathrm{i}$ future employment decisions. In this study, $\mathrm{X}_{1}$ to $\mathrm{X}_{5}$ are independent variables that may influence the future employment decision of a poultry farmer.

Where;

$\mathrm{X}_{1}=$ Years of formal education of the poultry farmer (years)

$\mathrm{X}_{2}=$ Age of farmer (Years)

$\mathrm{X}_{3}=$ Years of experience in poultry production (years)

$\mathrm{X}_{4}=$ Total amount of compensation received ( $\left.\#\right)$

$\mathrm{X}_{5}=$ Quantity of stock lost (actual number)

\section{Results and discussion}

\subsection{Monetary value of stock lost and future employment option of poultry farmers}

The monetary value of stock lost due to the outbreak of Avian Influenza in the study area is presented in Table 1. The outbreak was highest in Kuje followed by Bwari Area council. The future employment option of the poultry farmers is presented in Table 2. The table revealed that majority of the poultry farmers have either abandoned or reduced the scale of their poultry business. Majority of the poultry farmers decided to diversify from poultry business due to the inadequate amount of compensation received from government as well as reduced patronage by the customers after the outbreak of Avian Influenza.

\subsection{Factors that determine the future employment decisions of poultry farmers}

The Factors that determine future employment decisions of the poultry farmers are presented in Table 3 . The results revealed that the likelihood ratio test for the model Lambda $(\lambda)$ was 12.76 and was significant at $5 \%$. This means that the future employment options of the poultry farmers are heterogeneous. This finding confirms the appropriateness of the polychotomous model in the study. The table also revealed that three variables are likely to increase the probability of the farmer to decide on reducing the scale of production namely; level of education of the farmer, years of experience in poultry production and amount of compensation received. This implies that the three variables are associated with a higher probability of being in the choice group under consideration relative to the reference group. Furthermore, farmers' level of education and amount of compensation received are likely to be associated with the probability of a poultry farmer deciding to abandon poultry production relative to the reference group. As expected well educated farmers are likely to have other types of trainings which can enable them invest outside the poultry sector. The amount of compensation received will also go along way in helping to re-start the business. However if the compensation is inadequate, poultry farmers will not be encouraged to take the risk again. The most likely decision will be to abandon the poultry business for a less risky one.

\subsection{Post Avian Influenza outbreak constraints}

The post avian influenza outbreak constraints are presented in Table 4. Reduced patronage by customers, inadequate compensation and lack of access to formal agricultural credit were the major constraints noted in the area. Among the problems reported, reduced patronage by the customers was ranked first followed by inadequate compensation. 


\section{Conclusion and recommendations}

The result of this study showed that many poultry farmers have abandoned the poultry business while some have reduced the scale of their poultry businesses. Abandoning of poultry business and reduction in the scale of poultry production will result in low production of poultry products with an attendant effect on the availability and prices of poultry products. Giving the importance of poultry production as a source of income and employment for many Nigerians, the followings are recommended.

- $\quad$ There is an urgent need for Government to mandate Poultry Farmers to take up Insurance policies with the Nigerian Agricultural Insurance Cooperation. This will help to guarantee adequate compensation at all times.

- $\quad$ Formal agricultural credit institutions who attempt to discriminate against poultry farmers should be sanctioned by the Central Bank of Nigeria.

Efforts should be intensified in the area of public enlightment and dissemination of up-to-date information on avian influenza infection and control in humans in order to restore consumer confidence.

\section{References}

Abuja Echo. (2007). A Bimonthly Journal. FCTA printers Abuja 5, 8-9.

Adegbola, AA. (1990). Poultry development in Nigeria, University Press, Ibadan. pp, $112-118$.

Babcock BA., Chaherli NM., \& Lakshminariayma, PG. (1995). Programme Participation and Farm Level Adoption of Conservation Tillage. Estimates from a multinomial Logit Model. Working paper 95-wp 136, Centre for Agricultural and Rural Development, Iowa State University, Ames, Iowa.

Central Bank of Nigeria. (2006). Annual Report, various Issues Abuja, Nigeria

Fasina, FO., Bisschop., SPR, Ibironke., AA \& Meseko., CA. (2009). Avian influenza risk perception among poultry workers in Nigeria [letter]. Emerg Infect Dis, DOI: 10.3201/eid1504.070159

FCT ADP. (2007). Federal Capital Territory Agricultural Development Project. 2004 Annual Report

Hagan., R. \& Brunner., A. (1988). Microbiology and infectious Diseases of domestic animals. Connel University press. USA

Maddala, GS. (1983). Limited Dependent and Qualitative Variables in Econometrics. Cambridge University Press, Cambridge UK

National Population Commission. (2006). National Population and Housing Census Report Abuja, Nigeria

Obayelu, AE. (2007). Socio-economic analysis of the impacts of avian influenza epidemic on households poultry consumption and poultry industry in Nigeria: empirical investigation of Kwara State. Livestock Research for Rural Development. Volume 19, Article \#4. Retrieved October 7, 2009, [Online] Available: http://www.lrrd.org/lrrd19/1/obay19004.htm.

Olarewaju, S. (2006). Bird flu may kill 70 million people. World Bank Journal, 5, 6-8.

Pan-African Control of Epizootics. (2006). APAI in Nigeria: The Standard operating procedures. Abuja. Animal watch magazine, 3,10-11.

Raufu, MO., Oyewo, IO., Oyedele., TS \& Ogunlana, OE. (2009). Economic Implication of Avian influenza on Poultry farmers in Ogun State, Nigeria. The Social Sciences, 4 (6), 644-648.

Saidu, L., Wakawa, AM., Abdu, PA. Adene, DF., Kazeem, HM., Ladan, KC., Abdu, M., Miko, RB., Fatihu, MY., Adamu, J., \& Mamman, PH. (2008). Impact of Avian Influenza in Some States of Nigeria. International Journal of Poultry

Science, 7 (9), 913-916.

UNDP. (2006). Avian Flu and its Implications. Spore bimonthly health journal, 10, 5-7.

You., L \& Diao., X. (2006). Assessing potential impact of avian influenza on poultry in West Africa: a spatial equilibrium model analysis. Journal of agric economics, 58(2),348-367 
Table 1. Monetary value of Poultry Birds lost to Avian influenza

\begin{tabular}{llll}
\hline Affected Area councils & No of birds & Unit price (N) & Total (N) \\
\hline Gwagwalada & 14592 & 1000 & 14592000 \\
Municipal & 20134 & 1000 & 20134000 \\
Bwari & 38248 & 1000 & 38248000 \\
Kuje & 69767 & 1000 & 69767000 \\
Grand Total & $\mathbf{1 4 2 7 4 1}$ & & $\mathbf{1 4 2 7 4 1 0 0 0}$ \\
\hline
\end{tabular}

$¥ 154=1 \mathrm{USD}$

Table 2. Future employment options of poultry farmers

\begin{tabular}{lll}
\hline Future employment option & Frequency & Percentage \\
\hline & 9 & 22.5 \\
Continuing producing poultry & 18 & 45.0 \\
Abandoning poultry business & 13 & 32.5 \\
Reduction of scale of operation & 40 & 100.0 \\
Total & \\
\hline
\end{tabular}

Table 3. Multinomial logistic regression model of future employment decisions of Poultry farmers

\begin{tabular}{llc}
\hline Variables & reduction of scale of production & abandoning of poultry business \\
\cline { 2 - 3 } & Parameters & Parameters \\
\hline Education $\left(\mathrm{X}_{1}\right)$ & $0.280(0.532)^{*}$ & $0.668(0.432)^{* *}$ \\
Age $\left(\mathrm{X}_{2}\right)$ & $0.461(0.631)$ & $0.178(0.575)$ \\
Years of Experience in & & \\
Poultry Production $\left(\mathrm{X}_{3}\right)$ & $0.393(0.748)^{* * *}$ & $0.294(0.656)$ \\
Amount of Compensation & & $1.133(0.000)^{*}$ \\
received $\left(\mathrm{X}_{4}\right)$ & $2.001(0.00)^{*}$ & $3.579(0.000)^{*}$ \\
Quantity of stock lost $\left(\mathrm{X}_{5}\right)$ & $5.599(0.000)$ & $3.317(2.13)$ \\
Constant & $2.610(1.986)$ & \\
Log likelihood & -72.812 & \\
Likelihood Ratio $(\lambda)$ & $12.74^{*}$ & \\
$\mathrm{n}$ & 40 & \\
\hline
\end{tabular}

Note: Figures in parenthesis are the standard error of the estimated coefficients

*Significant at 10\% level of Significance

** Significant at 5\% level of Significance

$* * *$ Significant at $1 \%$ level of Significance

$\mathrm{n}=$ sample size 
Table 4. Post Avian influenza outbreak constraints

\begin{tabular}{llcl}
\hline Constraints & Frequency & Percentage & Rank \\
Reduced patronage by customers & 37 & 33.04 & $1^{\text {st }}$ \\
Inadequate compensation & 33 & 29.46 & $2^{\text {nd }}$ \\
No compensation & 11 & 9.82 & $4^{\text {th }}$ \\
Difficulties in obtaining formal & & & \\
Agric. Credit & 31 & 27.68 & $3^{\text {rd }}$ \\
Total & $112^{*}$ & 100.00 & \\
\hline
\end{tabular}

* Multiple response was allowed, hence total frequency exceeded the total sample size 